\title{
Some considerations concerning the challenge of incorporating social variables into epidemiological models in infectious disease transmission
}

Tony Barnett ${ }^{1}$, Guillaume Fournié2 ${ }^{2}$ Sunetra Gupta ${ }^{3}$, Janet Seeley ${ }^{4}$

\begin{abstract}
:
Incorporation of 'social' variables into epidemiological models remains a challenge. Too much detail and models cease to be useful; too little and the very notion of infection - a highly social process in human populations - may be considered with little reference to the social. The French sociologist Émile Durkheim proposed that the scientific study of society required identification and study of 'social currents'. Such 'currents' are what we might today describe as 'emergent properties', specifiable variables appertaining to individuals and groups, which represent the perspectives of social actors as they experience the environment in which they live their lives. Here we review the ways in which one particular emergent property, hope, relevant to a range of epidemiological situations, might be used in epidemiological modelling of infectious diseases in human populations. We also indicate how such an approach might be extended to include a range of other potential emergent properties to represent complex social and economic processes bearing on infectious disease transmission.
\end{abstract}

Keywords: translational epidemiology, social factors, structural 'drivers', infectious diseases, hope

\section{The problem:}

The interface between theoretical epidemiology and public health practice is complex and raises significant philosophical/methodological and practical questions. This paper discusses some aspects of this interface with regard to the modelling of infectious diseases. However, its prime goal is to consider how we might integrate significant social science variables into epidemiological models.

Theoretical epidemiology and practical/field epidemiology are different facets of epidemiological practice. Together they inform the discipline of public health. Theoretical epidemiology is the applications of "simple mathematical models of the transmission of infectious agents within human communities $^{5}$... to help interpret observed epidemiological trends, to guide the collection of data toward further understanding, and to design programmes for the control of infection and disease." (R Anderson \& R May, Infectious Diseases of Humans: dynamics and control, OUP, 1991). Practical/field epidemiology is the "the study of the occurrence and distribution of health-related states or events in specified populations, including the study of determinants influencing such states, and the application

\footnotetext{
${ }^{1}$ Department of Global Health and Development, London School of Hygiene and Tropical Medicine and Department of Social Policy, London School of Economics and Political Science

${ }^{2}$ Royal Veterinary College, London

${ }^{3}$ Department of Zoology, University of Oxford

${ }^{4}$ London School of Hygiene and Tropical Medicine \& UK MRC/UVRI Uganda Research Unit on AIDS

${ }^{5}$ This approach is not restricted to human populations but applies to all populations of living things.
} 
of this knowledge to control the health problems." (M Portas, A Dictionary of Epidemiology, OUP, 2008, p. 81).

There seems an obvious and direct connection between theoretical epidemiology and the pursuit and understanding of public health, defined as: "the science and art of preventing disease, prolonging life and promoting health through the organized efforts and informed choices of society, organizations, public and private, communities and individuals." (Winslow, Charles-Edward Amory (Jan 9, 1920). Further, the connection between practical/field epidemiology and public health seems self-evident. Practical/field epidemiology describes the distribution of a disease phenomenon, typically over time, space and (in human populations) significant (to the policy maker/public health practitioner) social differentiations. Most typically, in times of an "outbreak", it describes the source and likely distribution of the event. An example of theoretical epidemiology may be represented by Anderson and May's text book, cited above; an example of field epidemiology as part of a public health response may be represented by Sugunan and colleagues' study of an outbreak of cholera in the Andaman and Nicobar Islands in 2002 (Sugunan, Ghosh et al. 2004); and an example of mathematical modelling having a clear impact on policy is represented by Anderson and May's study of the impact of vaccination against rubella and measles (Anderson and May 1983). More recently, the notion of 'translational epidemiology' has been used to describe explicit attempts to translate scientific discoveries in epidemiology into population and public health impacts (Khoury, Gwinn, \& loannidis, 2010; Ward, Gregson, Watts, \& Garnett, 2014). This paper sits within that framework, arguing that if: (1) population/public health is a social endeavour, then (2) it is necessary to find innovative ways of building truly sociological variables into epidemiological models. We begin with the concept of the model.

A model is an abstraction of a system. It is a common fallacy that such an abstraction nonetheless resembles the system in all its visible aspects. However, this is most certainly not the case. While a three-dimensional model or architect's plan of a house may each resemble the object it represents; it remains a simplification of that object. So to do the mathematical statements describing any physical phenomenon. To those untrained in mathematics, a mathematical argument describing the functional relationships between defined variables of a system related to the world of disease transmission, may not be immediately accessible. Yet for those making the argument: (a) the selected variables are taken to be the critical to proper representation of some the essential features of the object being modelled; (b) the relationships between these variables are described by a set of mathematical statements which are mathematically true or false independently of the particular system being modelled.

The last observation requires elaboration. It engages a well-known and indeed fundamental philosophical question: the relation between mathematics and the world. The only necessary relationships between the mathematical models and the reality they are used to explore are that: a) they faithfully render the relationships between the physical analogues of the components of the models and $b$ ) the purely mathematical relationships are congruent to the patterns and processes in the physical world. To understand why this is the case, it is important to recall that it is not that maths just happen to describe aspects of the natural world. Although created as an abstract system of thought by human minds, maths does describe the natural world because the human mind is a product of that world and therefore, when it thinks mathematically, it describes aspects of the patterns and relations to be found in itself and in the materials from which it is made. 
Modelling involves simplifying reality in an attempt to understand the world by reducing it to a set of key variables and their functional relationships such that the model is able to provide an insight into reality that could not be obtained by mere examination. Thus "...models are not merely or mainly representations of phenomena; they are flexible tools that configure the domain, constitute its objects, and display salient features..." ${ }^{6}$. This directs attention to the multiple ways in which model construction is itself a social, cultural and political process (Mansnerus, 2006; Morgan, 2012). It is also a metaphorical process (Barnett, 2012).

Endlessly complicating epidemiological models by adding components has proved to be of limited value. While the organising rule may be parsimony, the temptation must be to compensate for any poverty of approximation to the phenomena being modelled by adding more variables. Of course, in principle, increasing complexity leads logically to reproduction of the object rather than modelling of it. Hence, the modelling process becomes a balancing act between parsimony and addition of variables where maximum parsimony with maximum explanatory power is the desired heuristic goal.

\section{Modelling infectious disease transmission}

Where infectious disease transmission is being modelled, the challenge may be to add variables and functions which represent assumed aspects of human behaviour which are germane to transmission. Such attempts to understand transmission may take into consideration a wider range of "social" or "economic" variables, representing theoretically derived significant groups such as occupational or income classes, gender, spatial classes, ethnic identities, migration status, \&c \&c. The connections between these variables may be described by such general terms "mixing patterns" or "contact networks" (Ward et al., 2014). Thus, in the case of STIs, sexual mixing patterns are significant $t$ (Adimora \& Schoenbach, 2005; Aral et al., 1999; Garnett \& Anderson, 1993, 1994; Gupta, Anderson, \& May, 1989; Jennings, Glass, Parham, Adler, \& Ellen, 2004; Kyung-Hee, Operario, Gregorich, \& Lei, 2003), while, in that of pandemic influenza, child-child and child-adult mixing patterns are significant (Fedson, 2005; Ferguson, Fraser, Donnelly, Ghani, \& Anderson, 2004; Pham Ngoc et al., 2006; Poland, Jacobson, \& Targonski, 2007; Rahamat-Langendoen, van Vliet, \& Suijkerbuijk, 2006; Schenzle, 1984; Ungchusak et al., 2005), or more broadly rates of mixing within and between age cohorts may be an important variable. It is feature of most epidemiological systems that such patterns are notoriously difficult to measure.

The practical public health questions a model aims to address influence the level of model complexity (Bruch \& Atwell, 2013). While a given epidemiological pattern can be described with a parsimonious model incorporating aggregated variables, assessment of the effectiveness of control or surveillance scenarios targeted to a social, economic or spatial stratum or segment of the population will require disaggregating those variables, and introducing new parameters. Such models can be seen as more "realistic", as they better account for population heterogeneity and include more details about disease transmission pathways. Yet, estimation of these additional parameters is also associated with some levels of uncertainty, contributing to the overall uncertainty of the model outcomes. While the increase in model complexity can be driven by practical, public health questions that need to

\footnotetext{
${ }^{6}$ This is a quote from a review of Mary Morgan's book The World in the Model by Catherine Z. Elgin of Harvard University, http://www.amazon.co.uk/The-World-Model-Economists-Think/dp/0521176190 accessed 21 May 2014.
} 
addressed (and also by increasing computing capability), the resulting uncertainty in the model outcomes may be so large that such models may be of little value to their initial purpose.

The fit of a model to an observed epidemiological pattern, e.g. an incidence curve, is often interpreted as a validation of the relevance of the modelled processes for the epidemiology of the studied disease. Such models are then modified to integrate various control scenarios, and to assess their effectiveness if these control strategies are to satisfy a given condition, for instance, disease elimination. Yet, the initial fit to the observed epidemiological pattern does not guarantee that the model incorporating control scenarios is still valid (and in any case, 'fitting' a model to data is intrinisically problematic if too many parameters are involved.) This is because control activities are generally modelled as though they are exogenous to the system: in other words, they would not modify risky behaviours or processes others than those they target. For instance, preventive measures may often be limited to their direct impact on the probability of a given contact resulting in infection, while their indirect impact on, for instance, mixing patterns will be ignored. The fact that a given set of processes allows reproduction of an epidemiological pattern, does not mean that they remain relevant when that "context" has been modified by, for instance, implementation of control interventions.

\section{From models to action}

We now consider the problem of how to move from the output of an abstract model to arriving at decisions as to how to act in the world? Model outputs form a probability distribution. It is from such distributions, combined with other information - for example, political, financial and ethical constraints to action - that policy-makers choose as they decide upon practical politics and actions. The primary problem is the significant loss of power to understand and predict behaviour as complexity is added to a model. However, even if it were possible to reliably construct a complex mathematical model incorporating all of the seemingly relevant variables (and variation therein), we would still be faced with the problem of obtaining reasonable estimates of the important parameters, particularly those pertaining to social behaviour. One particular social behaviour, sexual behaviour, presents a particular challenge where models of STIs are concerned.

Here we propose an approach that seeks to address both of these problems by: (a) developing a new analytical method that bypasses the errors inherent in the measurement of some particular types of long standing (and highly contentious and debated) forms of social categorisation; (b) preserving the requirement for parsimony in mathematical models in order that they can continue to be of practical and theoretical value in our understanding of infectious disease transmission.

To these ends, individual behaviours may be thought of as aggregating into emergent orders. In classical sociology, these have often been described as "institutions," although emergent orders are not necessarily the same as 'social institutions' and emergent orders may even turn out to be 'latent structures' of which social actors may be unaware or barely aware. Looked at from the perspective of the emergent properties of systems in general, and here of social systems in particular, we point to the potential of examining these emergent properties so as to be able to say something about how collective behaviours of various kinds regulate exposure to hazards of which infectious disease acquisition is a sub-type. So we must consider what we mean by social behaviour. 
Over the last few years, several mathematical models have explored how interactions between individuals may influence emergence of specific behaviours (Grund, Waloszek, \& Helbing, 2013) and how adaptive behaviours may impact on disease dynamics (Funk, Salathé, Vincent \& Jansen, 2010; Perrings et al., 2014). Individual behaviours and their determinants are often explicitly modelled based on the behavioural assumptions of neoclassical microeconomics (Epstein, Parker, Cummings, \& Hammond, 2008). We do not concern ourselves here with how individual actions aggregate into emergent properties. This is indeed an extremely important scientific question, which has rightly received considerable attention (Bruch \& Atwell, 2013; Grimm \& Railsback, 2004; Grimm et al., 2005; Levin, 1999). Instead, we propose treating emergent properties as variables of interest in understanding social behaviours relevant to infectious disease transmission; variables and processes leading to the emergence of these properties would not be modelled.

Thus, rather than seeking the origins of the emergent orders, we propose adopting an empirical approach by identifying and measuring significant emergent properties and including these directly as variables in a model. This approach does not necessarily adopt the behavioural assumptions of neoclassical economics and may well integrate behavioural assumptions that take account of local understandings and theories in the sense that Max Weber used that term (Weber, 1978), understanding the world as rational from the actor's perspective. In other words, understanding the world in ways commonly deployed in anthropological understandings of people's behaviour in the face of infectious diseases (Hewlett \& Amola, 2003; Leach, 2010, 2014; Parker \& Allen, 2013). This means taking account of actors' understanding of situations, understandings which may appear 'irrational', but understandings and beliefs that are nonetheless at least partial determinants of individuals' and groups' actions.

\section{Social behaviour and emergent properties}

It might be argued that all human behaviour is in some respect "social". The question is what kinds of conceptualisation of behaviour is useful such that it both: a) represents that behaviour and b) informs epidemiological models, so they "capture" behaviours in ways which enhance our understanding of the socio-economic and socio-cultural processes of infectious disease transmission?

The relevant types of behaviour for this kind of analysis should meet the following criterion: they would be able to epitomise the influence of diverse and powerful sets of social, economic and cultural influences. But such analysis and causal influence of each of which would require huge and probably very long term and contentious debate. Here we do not follow that analytical path; nor do we engage with those debates at any length. Instead, we adopt a new approach by introducing analytically derived variables which can be operationalised and combine individuals' subjective experience of their social, economic and cultural milieu by summarising their experience of social, cultural and economic life, capturing the point at which their agency is constrained by social structure. This type of variable can be thought of as an emergent property of social, cultural and economic life. We believe that such variables are able to bring together the perspectives of the social person looking out on their experience of how social structures, cultural demands and economic imperatives facilitate, limit or encourage personal choices. 
One such emergent property variable - but almost certainly not the only one - is the variable "hope" (Barnett 2008; Barnett and Weston 2008). Here this stands as an exemplar of the process of using such an emergent property variable might be used. Its use is discussed and analysed at greater length elsewhere (Barnett, Seeley, Levin, \& Katongole, 2015). Hope is a variable that: 1 ) captures the individual's experience of their social, economic, cultural and political environment looking out from within their place in that milieu; and 2) when aggregated for a population or sub-population (for example an income or occupational class, a gender identity, a status group, an ethnic group) captures that population or sub-population's experience.

In each case, the variable hope (as measured using a rigorous and validated instrument) potentially provides a datum for input into an epidemiological model as socio-cultural or socio-economic modulators of the rates at which individuals and thus collectivities became infected. In addition to the variable hope, other possible emergent properties which could be used in the same way and also in principle be represented now or in the future by validated scales include: fear, disgust (Curtis 2013), pp. 186-9, aspiration, optimism, nationalism, patriotism, cynicism, or even a general tendency toward biased judgements about social groups (Banaji and Greenwald 2013). These variables are likely to influence risk behaviours in many ways, most obviously in the case of disgust and the likelihood of orofaecal pathogen exposure (Curtis, 2013). However, individual or group decision perspectives influenced by high or low hope may affect exposure to infection. For example, a destitute woman's decision/capability to insist her sexual partner use a condom will be conditioned, to a degree, by her level of hope about the likelihood of being able to earn an income alternative to the 'gift' he will give her in the morning. We suggest that individual and group hope schedules affect individual and group risk perception and behaviour, and that there is a relationship between hope, risk exposure and acquisition of HIV and/or behaviours known to be associated with risk of HIV acquisition (Barnett \& Blaikie, 1992; Worth, 1989). Such proposed variables could be used cross culturally to describe aspects of a society (or for that matter of a social group or subset within a society) which are likely (and this has to be tested and so stands for the moment only as an hypothesis) to influence and represent social behaviours relevant to the rates of acquisition of infectious diseases under different circumstances.

\section{Social currents}

This idea is not entirely new; indeed these emergent property variables have very deep roots in sociological theory. They may be thought of as having the characteristics of social currents as this term was invented and used by the sociologist Emile Durkheim (Durkheim, Solovay et al. 1965; Durkheim and Simpson 1970). Some of these categories describe important non-rational ${ }^{7}$ behaviours which have social implications. It is important to have these non-rational elements at least in part because so much health education intervention theory to contain infectious diseases has depended heavily on rational choice and allied rationalistic approaches to human behaviour (Fishbein and Ajzen 1975). In contrast, we know from the public understanding of science literature that non-rational

\footnotetext{
${ }^{7}$ This in no sense means irrational. The source for this use of the term here is Max Weber's characterisation of the types of action, a typology derived from a means-end schema in which the rational types of action, zweckrationalität, wertrationalität, affectual and traditional action sit alongside a poorly defined realm of what Weber considers to be "non-social" behaviour, see: Weber, M. and T. Parsons (1947). The theory of social and economic organization. Glencoe, III., Free Press. This is the focus of the paragraph.
} 
behaviour is of very considerable importance in people's understanding of infectious disease and for what often turn out to be very sophisticated reasons which engage with significant questions about science as a probabilistic practice (Rubincam 2013), a modus operandi often obscured in the public mind by the authoritative image of the white-coated male expert.

In a wider and different theoretical context, that of evolutionary biology, such forms of action are described by Aunger and Curtis (Aunger and Curtis 2013) as "motives" 8 and suggested as having their origins in the evolutionary history of human beings (and indeed other animals). These authors identify fifteen human motives, which they list as: lust, hunger, comfort, fear, disgust, attract, love, nurture, create, hoard, affiliate, status, justice, curiosity, and play. They suggest these motives are consistent with evidence from the current literature and provide "a precise vocabulary for talking about motivation". Although these authors do not make this claim, it seems possible that such concepts might in the future be developed and deployed as scalable and measurable emergent variables to populate and calibrate models of social and economic behaviour including that which underlies transmission of infectious diseases between human beings.

\section{Conclusion}

So far, we have undertaken some limited survey and ethnographically informed field studies in Uganda. These are soon to be replicated in Tanzania as a wider theoretical and empirical study of the emergent variable hope of which the present paper forms a part. In the Uganda study, we investigate how far and in what ways the variable hope is statistically related to conditions known to favour the acquisition of HIV. We are doing this in the belief that aspects which we would not traditionally regard as quantifiable - such as hope - are in reality more quantifiable than concepts like "risk factors" and "drivers". The former term has been used to refer to correlational associations between an epidemiologically significant variable (for example acquisition of a disease) and another variable (exposure to polluted water) which, while strongly suspected to be associated with disease acquisition, may or may not be causal in its association with that variable. The latter term, driver, has in recent years been frequently used to describe the ways in which micro (individual) and macro (institutional, systemic) elements affect the risk of infection (Gupta 2008; Auerbach 2011; Parkhurst 2013). Although we have sketched a range of possible emergent property variables in the preceding, for the moment we are centrally focused on a test variable representing this general type of emergent property variable. We are doing this to present and begin to test the view that such a variable:

1. Captures individuals' experience of their social, economic, cultural and political environment looking out from within their place in that milieu;

2. When aggregated for a population or sub-population (for example an income or occupational class, a gender identity, a status group, an ethnic group) captures that population or sub-population's experience;

3. When measured using a rigorous and validated instrument potentially provides a datum for input into epidemiological models as socio-cultural or socio-economic modulators of the rates at which individuals and thus collectivities became infected.

4. If feasible and practicable would provide a way forward from the view that such is the complexity of, for example, human sexual partner choices, that it is in practice too difficult to specify them mathematically (Anderson, Gupta, \& Ng, 1990).

\footnotetext{
${ }^{8}$ Elsewhere a related analysis of some of these described as "emotions" is offered by Denton, D. (2009). The Primordial Emotions: the dawning of consciousness. Oxford, Oxford University Press.
} 
That we might measure an individual and emergent variable, hope, is an innovative idea. It arises from realisation that, while measuring mixing patterns is very difficult, the emergent variable hope, a variable which 'shrinks' a wide range of very complex socio-economic and cultural variables into a summary variable, might actually be measurable and serve as a better indicator of epidemic behaviour than those more conventional, non-sociological measures used in disease modelling in relation to HIV/AIDS and other infectious diseases.

\section{Funding}

This work benefited from an Economic and Social Research Council (ESRC) Professorial Fellowship award to Tony Barnett (RES 051-27-0016). Both Tony Barnett and Guillaume Fournié currently receive funding from the research programme 'Controlling and monitoring emerging zoonoses in the poultry farming and trading system in Bangladesh: an interplay between pathogens, people, policy'. This is one of 11 programmes funded under ZELS, a joint research initiative between Biotechnology and Biological Sciences Research Council (BBSRC), Defence Science and Technology Laboratory (DSTL), Department for International Development (DFID), Economic and Social Research Council (ESRC), Medical Research Council (MRC) and Natural Environment Research Council (NERC). 


\section{Bibliography}

Adimora, A. A., \& Schoenbach, V. J. (2005). Social context, sexual networks, and racial disparities in rates of sexually transmitted infections. Journal of Infectious Diseases, 191(Suppl. 1), S115S122. doi:10.1086/425280

Anderson, R. M., Gupta, S., \& Ng, W. (1990). The significance of sexual partner contact networks for the transmission dynamics of HIV. JAIDS Journal of Acquired Immune Deficiency Syndromes, 3, 417-429.

Anderson, R., \& May, R. (1983). Vaccination against rubella and measles: Quantitative investigations of different policies. Journal of Hygiene (Cambridge), 90, 259-325. doi:10.1017/S002217 $240002893 X$

Anderson, R. M., \& May, R. M. (1991). Infectious diseases of humans: Dynamics and control. Oxford: Oxford University Press.

Aral, S. O., Hughes, J. P., Stoner, B., Whittington, W., Handsfield, H. H., Anderson, R. M., \& Holmes, K. K. (1999). Sexual mixing patterns in the spread of gonococcal and chlamydial infections. American Journal of Public Health, 89, 825-833. doi:10.2105/AJPH.89.6.825

Auerbach, J. D., Parkhurst, J. O., \& Cáceres, C. (2011). Addressing social drivers of HIV/AIDS for the long-term response: Conceptual and methodological considerations. Global Public Health, 6(Suppl. 3), S293-S309. doi:10.1080/17441692.2011.594451

Aunger, R., \& Curtis, V. (2013). The anatomy of motivation: An evolutionary-ecological approach. Biological Theory, 8(1), 49-63. doi:10.1007/s13752-013-0101-7

Aunger, R., \& Curtis, V. (in press). Gaining control: Major transitions in the evolution of complex behaviour. Oxford: Oxford University Press. Retrieved from http://ukcatalogue.oup.com/product/ 9780199688951.do

Banaji, M., \& Greenwald, A. (2013). Blindspot: Hidden biases of good people. New York, NY: Delacorte Press. Barnett, T. (2008). HIV/AIDS and hope (lessness). Global Public Health, 3, 233-248. doi:10.1080/17441690801920207

Barnett, T. (2012). Social policy interventions to enhance the HIV/AIDS response in sub-Saharan Africa: Alternative perspectives-Sets, metaphors and hope. In B. Lomborg (Ed.), RethinkHIV: Smarter ways to invest in ending HIV in Sub-Saharan Africa (pp. 281-292). Cambridge: Cambridge University Press.

Barnett, T., \& Blaikie, P. M. (1992). AIDS in Africa: Its present and future impact. New York, NY: Belhaven Press, London and Guildford Press.

Barnett, T., Seeley, J., Levin, J., \& Katongole, J. (2015). Hope: A new approach to understanding structural factors in HIV acquisition. Global Public Health, 10(4). Advance online publication. doi:10.1080/17441692.2015.1007154

Barnett, T., \& Weston, M. (2008). Health, wealth, HIVand the economics of hope. AIDS, 22(Suppl. 2), S27-S34. doi:10.1097/01.aids.0000327434.28538.51

Bruch, E., \& Atwell, J. (2013). Agent-based models in empirical social research. Sociological Methods \& Research, 1-36. doi:10.1177/0049124113506405 
Curtis, V. (2013). Don't look, don't touch: The science behind revulsion (1st ed.). Oxford: Oxford University Press. Denton, D. (2009). The primordial emotions: The dawning of consciousness. Oxford: Oxford University Press.

Durkheim, É., \& Simpson, G. (1970). Suicide: A study in sociology. [S.I.]. London: Routledge \& K P. Global Public Health 9 Downloaded by [86.137.156.3] at 14:57 06 February 2015 Durkheim, É., Solovay, S. A., \& Mueller, J. H. (1965). The rules of sociological method (8th ed., Sarah A. Solovay, Trans., and J. H. Mueller, Ed.). [S.I.].

Glencoe, IL: The Free Press. Epstein, J. M., Parker, J., Cummings, D., \& Hammond, R. A. (2008). Coupled contagion dynamics of fear and disease: Mathematical and computational explorations. PLoS ONE, 3(12), 1-11. doi:10.1371/journal.pone.0003955

Fedson, D. S. (2005). Preparing for pandemic vaccination: An international policy agenda for vaccine development. Journal of Public Health Policy, 26(1), 4-29. doi:10.1057/palgrave. jphp.3200008

Ferguson, N., Fraser, C., Donnelly, C., Ghani, A., \& Anderson, R. (2004). Public health. Public health risk from the avian H5N1 influenza epidemic. Science, 304, 968-969. doi:10.1126/ science.1096898

Fishbein, M., \& Ajzen, I. (1975). Belief, attitude, intention and behavior: An introduction to theory and research. Reading, MA and London: Addison-Wesley.

Funk, S., Salathé, M., Vincent, A. A., \& Jansen, A. (2010). Modelling the influence of human behaviour on the spread of infectious diseases: A review. Journal of the Royal Society Interface, 7, 12471256. doi:10.1098/rsif.2010.0142

Garnett, G. P., \& Anderson, R. M. (1993). Factors controlling the spread of HIV in heterosexual communities in developing countries: Patterns of mixing between different age and sexual activity classes. Philosophical Transactions of the Royal Society of London. Series B Biological Sciences, 342, 137-159. doi:10.1098/rstb.1993.0143

Garnett, G. P., \& Anderson, R. M. (1994). Balancing sexual partnerships in an age and activity stratified model of HIV transmission in heterosexual populations. IMA Journal of Mathematics Applied in Medicine and Biology, 11, 161-192. doi:10.1093/imammb/11.3.161

Grimm, V., \& Railsback, S. F. (2004). Individual-based modeling and ecology. Princeton, NJ \& Oxford: Princeton University Press \& Oxford University Press.

Grimm, V., Revilla, E., Berger, U., Jeltsch, F., Mooij, W. M., Railsback, S. F., ... DeAngelis, D. L. (2005). Pattern-oriented modeling of agent-based complex systems: Lessons from ecology. Science, 310(5750), 987-991. doi:10.2307/3842807

Grund, T., Waloszek, C., \& Helbing, D. (2013). How natural selection can create both self- and otherregarding preferences, and networked minds. Scientific Reports, 3, 1-15. doi:10.1038/ srep01480

Gupta, S., Anderson, R. M., \& May, R. M. (1989). Networks of sexual contacts: Implications for the pattern of spread of HIV. AIDS, 3, 807-818. doi:10.1097/00002030-198912000-00005

Gupta, G. R., Parkhurst, J. O., Ogden, J. A., Aggleton, P., \& Mahal, A. (2008). Structural approaches to HIV prevention. The Lancet, 372, 764-775. doi:10.1016/S0140-6736(08)60887-9 
Hewlett, B. S., \& Amola, R. P. (2003). Cultural contexts of Ebola in Northern Uganda. Emerging Infectious Diseases, 9, 1242-1248. doi:10.3201/eid0910.020493

Jennings, J., Glass, B., Parham, P., Adler, N., \& Ellen, J. M. (2004). Sex partner concurrency, geographic context, and adolescent sexually transmitted infections. Sexually Transmitted Diseases, 31, 734-739. doi:10.1097/01.olq.0000145850.12858.87

Khoury, M. J., Gwinn, M., \& loannidis, J. P. A. (2010). The emergence of translational epidemiology: From scientific discovery to population health impact. American Journal of Epidemiology, 172, 517-524. doi:10.1093/aje/kwq211

Kyung-Hee, C., Operario, D., Gregorich, S. E., \& Lei, H. (2003). Age and race mixing patterns of sexual partnerships among Asian men who have sex with men: Implications for HIV transmission and prevention. AIDS Education \& Prevention, 15(Suppl. A), 53. doi:10.1521/ aeap.15.1.5.53.23609

Leach, M. (2010). In this month's Bulletin. Bulletin of the World Health Organization, 88, 481. doi:10.2471/BLT.10.000710 Leach, M. (2014). Ebola in Guinea: People, patterns and puzzles. The Lancet Global Health Blog. Retrieved from http://globalhealth.thelancet.com/2014/04/03/ebola-guinea-people-patterns-andpuzzles

Levin, S. (1999). Fragile dominion. Cambridge, MA: Perseus Publishing. Mansnerus, E. (2006). Questions to artificial nature: A philosophical study of interdisciplinary models and their functions in scientific practice. (Unpublished doctoral dissertation). University of Helsinki, Helsinki.

Morgan, M. S. (2012). The world in the model: How economists work and think. Cambridge: Cambridge University Press.

Parker, M., \& Allen, T. (2013). Will mass drug administration eliminate lymphatic filariasis? Evidence from Northern Coastal Tanzania. Journal of Biosocial Science, 45, 517-545. doi:10.1017/S0021932012000466

Parkhurst, J. O. (2013). Structural drivers, interventions, and approaches for prevention of sexually transmitted HIV in general populations: Definitions and an operational approach. Structural approaches to HIV prevention position paper series. Arlington, VA: USAID AIDS Support and Technical Assistance Resources, AIDSTAR-One, Task Order 1; London: UKaid's STRIVE research consortium.

Perrings, C., Castillo-Chavez, C., Chowell, G., Daszak, P., Fenichel, E. P., Finnoff, D., ... Springborn, M. (2014). Merging economics and epidemiology to improve the prediction and management of infectious disease. Ecohealth, 1-12. doi:10.1007/s10393-014-0963-6

Pham Ngoc, D., Hoang Thuy, L., Nguyen Thi Kim, T., Nguyen Tran, H., Le Thi Quynh, M., Le Hong, P., ... Nguyen Thi Minh, P. (2006). Risk factors for human infection with avian influenza A H5N1, Vietnam, 2004. Emerging Infectious Diseases, 12, 1841-847. doi:10.3201/eid1212. 060829

Poland, G. A., Jacobson, R. M., \& Targonski, P. V. (2007). Avian and pandemic influenza: An overview. Vaccine, 25, 3057-3061. doi:10.1016/j.vaccine.2007.01.050 Portas, M. (2008). A dictionary of epidemiology. Oxford: Oxford University Press.

Rahamat-Langendoen, J. C., van Vliet, J. A., \& Suijkerbuijk, A. W. (2006). Recognition of threats caused by infectious diseases in the Netherlands: The early warning committee. Euro Surveillance, 11, 242-245. 
Rubincam, C. (2013). Alternative beliefs about HIV/AIDS: Re-examining distrust among young adults in Cape Town, South Africa (Unpublished doctoral dissertation). London School of Economics and Political Science, London.

Schenzle, D. (1984). An age-structured model of pre- and post-vaccination measles transmission. Mathematical Medicine and Biology, 1, 169-191. doi:10.1093/imammb/1.2.169

Snyder, C. R., Sympson, S. C., Ybasco, F. C., Borders, T. F., Babyak, M. A., \& Higgins, R. L. (1996). Development and validation of the State Hope Scale. Journal of Personality and Social Psychology, 70, 321-335. doi:10.1037/0022-3514.70.2.321

Sugunan, A. P., Ghosh, A. R., Roy, S., Gupta, M. D., \& Sehgal, S. C. (2004). A cholera epidemic among the Nicobarese tribe of Nancowry, Andaman, and Nicobar, India. American Journal of Tropical Medicine and Hygiene, 71, 822-827.

Ungchusak, K., Auewarakul, P., Dowell, S. F., Kitphati, R., Auwanit, W., Puthavathana, P., ... Chunsutthiwat, S. (2005). Probable person-to-person transmission of avian influenza $A$ (H5N1). New England Journal of Medicine, 352, 333-340. doi:10.1056/NEJMoa044021

Ward, H., Gregson, S., Watts, C., \& Garnett, G. (2014). Translational epidemiology: Developing and applying theoretical frameworks to improve the control of HIV and other sexually transmitted infections. Journal of Infectious Disease Epidemiology, 210(Suppl. 2), S547-S548. doi:10.1093/infdis/jiu559

Weber, M. (1978). Economy and society: An outline of interpretive sociology. Oakland: University of California Press.

Weber, M., \& Parsons, T. (1947). The theory of social and economic organization. Glencoe, IL: Free Press. Winslow, C. E. (1920). The untilled fields of public health. Science, 51(1306), 23-33. doi:10.1126/ science.51.1306.23

Winslow, C. E. (1920). The untilled fields of public health. Science, 51(1306), 23-33. doi:10.1126/ science.51.1306.23

Worth, D. (1989). Sexual decision-making and AIDS: Why condom promotion among vulnerable women is likely to fail. Studies in Family Planning, 20, 297-307. doi:10.2307/1966433 